\title{
Research \\ Changes in skeletal muscle oxygenation during exercise measured by near-infrared spectroscopy on ascent to altitude

\author{
Daniel S Martin ${ }^{1}$, Denny ZH Levett ${ }^{1}$, Michael Mythen ${ }^{1,2}$ and Mike PW Grocott ${ }^{1}$, for the Caudwell \\ Xtreme Everest Research Group
}

\author{
${ }^{1}$ Centre for Altitude, Space and Extreme Environment Medicine (CASE Medicine), University College London Portex Unit, Institute of Child Health, \\ 30 Guilford Street, London WC1N 1EH, UK \\ ${ }^{2}$ UCLH/UCL Comprehensive Biomedical Research Centre, 1st Floor, Maple House, 149 Tottenham Court Road, London W1T 7NF, UK
}

Corresponding author: Daniel S Martin, dan.s.martin@gmail.com

Published: 30 November 2009

This article is online at http://ccforum.com/content/13/S5/S7

(c) 2009 BioMed Central Ltd
Critical Care 2009, 13(Suppl 5):S7 (doi:10.1186/cc8005)

\section{Introduction}

Interindividual tolerance to chronic hypoxaemia is highly varied and may determine survival in the clinical context. Specific mechanisms to explain this heterogeneous response to a sustained reduction in systemic oxygen availability remain unclear. Ascent to high altitude has been suggested as a paradigm for studying human responses to hypoxia in order to probe specific adaptive mechanisms pertinent to critical illness [1]. In combination with exercise, this can provide an effective method of manipulating the balance between oxygen supply and utilisation. In skeletal muscle this equilibrium of tissue oxygen metabolism governs exercise capacity, whilst amongst other organs it is one of the primary determinants of organ function.

The signal from near-infrared spectroscopy (NIRS) can be used to estimate skeletal muscle microcirculatory oxygenation, and principally reflects the venous haemoglobin oxygen status [2,3]. Skeletal muscle oxygenation decreases during exercise and the magnitude of this response is dependent on exercise intensity [4-6]. This desaturation occurs despite an increase in systemic oxygen flux, local vasodilatation leading to enhanced regional blood flow, and increased tissue oxygen extraction. The sustained reduction in exercise capacity, measured by maximal oxygen consumption $\left(\mathrm{VO}_{2 \text { max }}\right)$, at high altitude is a highly reproducible phenomenon despite adequate acclimatisation [7-10]. The precise mechanism of this persistent decline in exercise capacity remains unclear, but changes in oxygenation of the peripheral circulation detectable by NIRS may help elucidate the phenomenon and further our understanding of the adaptive mechanisms to chronic hypoxaemia in the clinical environment.

$\Delta \mathrm{StO}_{2}=$ difference in tissue oxygen saturation between stage means; NIRS = near-infrared spectroscopy; $\mathrm{SL}=$ sea level; $\mathrm{SpO}{ }_{2}=$ peripheral oxygen saturation; $\mathrm{StO}_{2}=$ tissue oxygen saturation; $\mathrm{StO}_{2}$ rate $=$ rate of change in tissue oxygen saturation; $\mathrm{VO}_{2 \text { max }}=$ maximal oxygen consumption. 
We hypothesised that, when measured at altitude, absolute values of skeletal muscle tissue oxygen saturation $\left(\mathrm{StO}_{2}\right)$ measured by NIRS would be lower than those at sea level (SL) both whilst resting and during exercise. We also hypothesised that the difference in $\mathrm{StO}_{2}$ from rest to maximal exercise would remain unchanged and the rate of desaturation would increase at altitude. We therefore sought to quantify the change in muscle oxygenation using NIRS during exercise on ascent to high altitude.

\section{Methods}

\section{Subject selection}

Ethical approval for the present study was obtained from the University College London Committee on the Ethics of NonNHS Human Research, and all participants gave written informed consent. The subjects were 24 healthy volunteers trekking to the base camp of Mount Everest $(5,300 \mathrm{~m})$ in spring 2007; six females and 18 males with a mean age of 35.2 years. This group consisted of two predetermined cohorts. All shared an identical ascent profile to $5,300 \mathrm{~m}$; climbers $(n=14)$ then ascended from $5,300 \mathrm{~m}$ to various altitudes, reaching a maximum elevation of $8,848 \mathrm{~m}$, whilst the base-camp team $(n=10)$ remained at $5,300 \mathrm{~m}$ for the duration of the study.

\section{Study settings}

Baseline measurements of exercising skeletal muscle $\mathrm{StO}_{2}$ were performed at SL $(75 \mathrm{~m})$ before departure to high altitude. Further measurements were taken at 3,500 m (days 4 to 6 of the expedition), on arrival at 5,300 m (5,300 m-a; days 15 to 17) and before departure from $5,300 \mathrm{~m}$ $(5,300 \mathrm{~m}-\mathrm{b}$; days 69 to 71$)$. Excessive exercise at altitude has been associated with an increased risk of acute mountain sickness [11]. Any subject suffering symptoms of acute mountain sickness at altitude was therefore not studied. Other exclusion criteria for cardiopulmonary exercise testing were based on the American Thoracic Society/American College of Chest Physicians guidelines for clinical exercise testing [12]; all subjects with an absolute or relative contraindication as defined by these guidelines were excluded from exercise.

\section{Measurement of skeletal muscle oxygenation}

Measurements were made using the InSpectra ${ }^{\text {TM }}$ Tissue Spectrometer (Model 325; Hutchinson Technology Inc., Hutchinson, MN, USA) incorporating a $15 \mathrm{~mm}$ probe. The spectrometer calculates $\mathrm{StO}_{2}$ by applying algorithms to the NIRS signal reflected from tissue below the probe:

$$
\begin{gathered}
\mathrm{StO}_{2}=(\text { Oxygenated haemoglobin concentration / } \\
\text { Total haemoglobin concentration }) \times 100
\end{gathered}
$$

The spectrometer was connected to a laptop computer for the storage of data during exercise. The NIRS probe was placed on the skin of the dominant thigh over the lower third of the vastus lateralis muscle, $10 \mathrm{~cm}$ proximal to the knee joint. Once a signal had been confirmed on the spectrometer, the probe was attached firmly with Elastoplast tape. Measurements from the spectrometer were recorded during the predetermined exercise protocol and 60 seconds into the rest period that followed exercise. The InSpectra ${ }^{\mathrm{TM}}$ Tissue Spectrometer recorded $\mathrm{StO}_{2}$ every 3 seconds during standard data collection, and a time-point marker was entered into the computer software to ensure synchronisation of exercise and $\mathrm{StO}_{2}$ data.

\section{Exercise protocol}

The subjects performed an incremental ramp test to the limit of tolerance using an electromagnetically braked cycle ergometer (Lode Corival; Lode, Groningen, the Netherlands) and a breathby-breath cardiopulmonary exercise testing system (Metamax 3b; Cortex, Leipzig, Germany). A full calibration of the breathby-breath system was performed before each test. Prior to the incremental exercise test, subjects warmed up with a lowintensity 30-minute constant work rate protocol. A ramp slope of 20 to $35 \mathrm{~W} /$ minute was chosen depending on the sex, age and physical fitness of the subjects in order to obtain a test duration of approximately 10 to 15 minutes [13]. The ramp slope was kept constant for all subjects throughout the study. Resting measurements were recorded for 3 minutes, followed by 3 minutes of unloaded cycling (ULC) and then the incremental ramped exercise protocol.

\section{Measurement of peripheral oxygen saturation}

Resting peripheral oxygen saturation $\left(\mathrm{SpO}_{2}\right)$ was measured using a pulse oximeter (Onyx 9500; Nonin, Plymouth, MN, USA) on the subject's right index finger.

\section{Analysis plan}

$\mathrm{VO}_{2 \text { max }}$ was calculated as the average oxygen consumption for the individual breaths taken in the final 20 seconds of the exercise test. The time for $\mathrm{VO}_{2 \text { max }}$ reported was the middle time point of the 20-second time interval. Data were plotted on graphs of $\mathrm{StO}_{2}$ versus time and were visually assessed for quality and completeness. A number of NIRS plots were rejected from analysis on the grounds that there was little or no change in signal from rest throughout the exercise protocol. These plots represented nonphysiological data, and other authors have adopted a similar quality control technique [14].

The resting $\mathrm{StO}_{2}$ was calculated as the average of readings during a 30 -second rest period before the exercise protocol started. Individual subject $\mathrm{StO}_{2}$ at each principle stage of the exercise protocol (end of 3 minutes ULC, $\mathrm{VO}_{2}$ max and 60 seconds after cessation of exercise) was calculated as the average of three recordings (spanning 9 seconds) around the designated time of occurrence. The mean (confidence interval) of these $\mathrm{StO}_{2}$ values is reported for each altitude along with differences between stage means $\left(\Delta \mathrm{StO}_{2}\right)$. The rate of change in $\mathrm{StO}_{2}\left(\mathrm{StO}_{2}\right.$ rate $)$ between the end of ULC and $\mathrm{VO}_{2 \text { max }}$ was calculated by dividing the difference in $\mathrm{StO}_{2}$ between stages by the time taken between stages. 

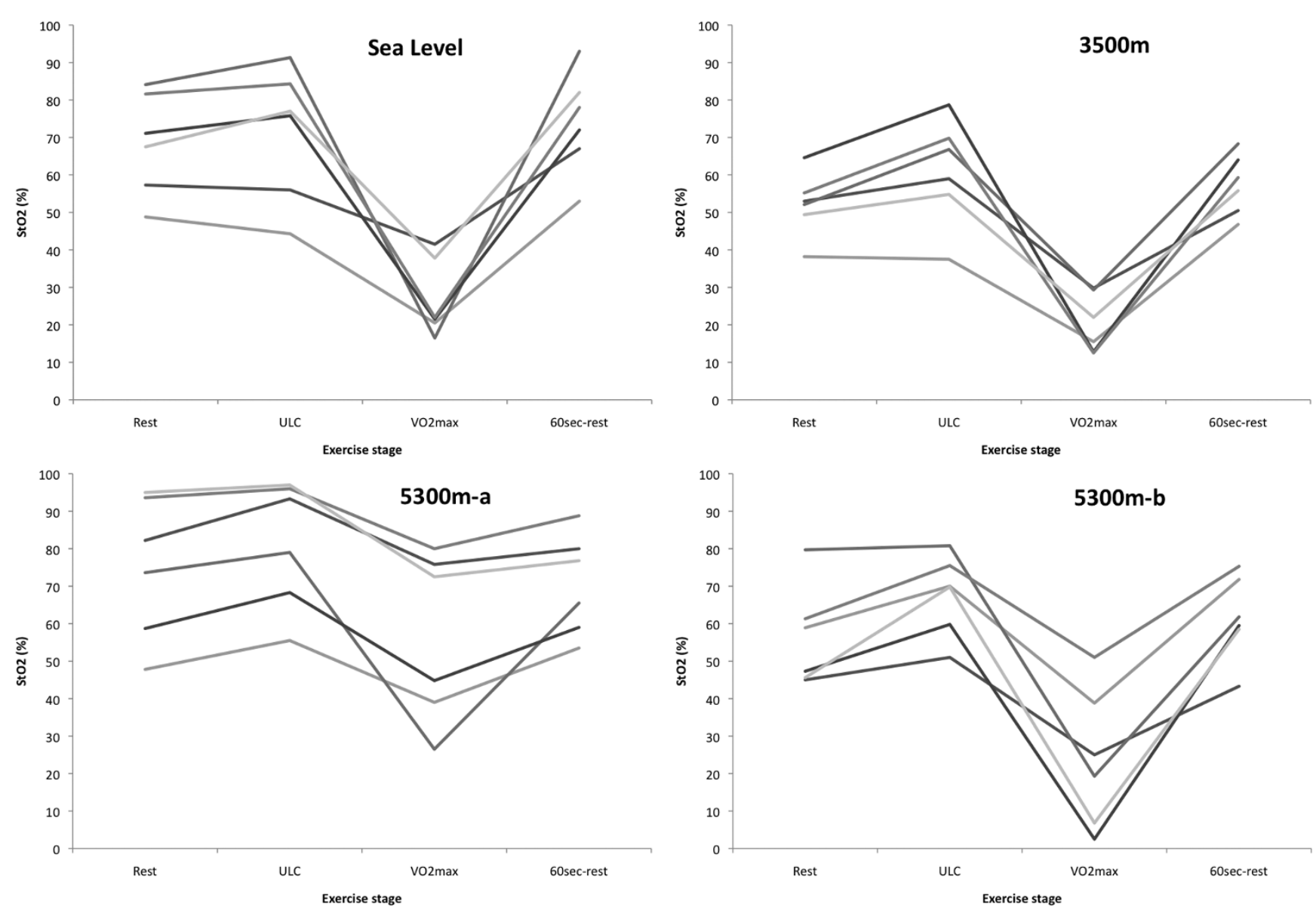

Individual changes in tissue oxygen saturation during exercise. Individual changes in tissue oxygen saturation $\left(\mathrm{StO}_{2}\right)$ during exercise in the subjects with complete data at all altitude time points $(n=6) .5300 \mathrm{~m}-\mathrm{a}$, on arrival at $5,300 \mathrm{~m}$ (days 15 to 17$) ; 5300 \mathrm{~m}$-b, before departure from $5,300 \mathrm{~m}$ (days 69 to 71); ULC, unloaded cycling; $\mathrm{VO}_{2 \text { max }}$ maximal oxygen consumption; 60 sec-rest, 60 seconds after completion of exercise.

Two-tailed paired $t$ tests were used to assess the affect of altitude on $\mathrm{StO}_{2}, \Delta \mathrm{StO}_{2}$ and $\mathrm{StO}_{2}$ rate. Comparison between groups containing different individuals was by unpaired $t$ test. Correlation between the rate of decline in $\mathrm{StO}_{2}$ and $\mathrm{SpO}_{2}$ was by Pearson's product-moment coefficient, and that between $\mathrm{StO}_{2}$ and nonparametric data was with Spearman's rank correlation coefficient. $P<0.05$ was taken to indicate statistical significance in all instances.

\section{Results}

\section{Data collection and quality control}

Data collection was incomplete due to a combination of technical difficulties and subjects failing to fulfil the inclusion criteria for exercise testing at altitude. All of the 24 subjects completed the exercise protocol at SL; missing the exercise protocol due to illness were two subjects at 3,500 m, one subject at 5,300 m-a and two subjects at 5,300 m-b. NIRS data were missing due to technical failure for four subjects at $\mathrm{SL}$, for two subjects at $3,500 \mathrm{~m}$ and for three subjects at $5,300 \mathrm{~m}$-a. Three subjects (all female) were completely removed from the analysis as part of the quality control screening. NIRS data meeting the predefined quality criteria were available for 18 subjects at SL, for 16 subjects at 3,500 $\mathrm{m}$, for 16 subjects on arrival at 5,300 $\mathrm{m}$ and for 16 subjects on departure from $5,300 \mathrm{~m}$. Only six subjects had complete data at each altitude time point, and their individual data can be seen in Figure 1. The data presented are all of the available data at each altitude time point.

\section{Changes in absolute tissue oxygen saturation during exercise}

The mean $\mathrm{StO}_{2}$ at rest, at the end of ULC, at $\mathrm{VO}_{2 \text { max }}$ and 60 seconds after $\mathrm{VO}_{2 \text { max }}$ are presented in Table 1 for each altitude along with the mean weight and resting $\mathrm{SpO}_{2}$. At SL, the mean $\mathrm{StO}_{2}$ increased by $6.7 \%$ during ULC, from a resting value of $74.4 \%$ (68.6 to 80.1 ) to $81.1 \%$ (73.8 to 88.3 ) $(P=0.001)$. The mean $\mathrm{StO}_{2}$ progressively declined during the incremental workload protocol to a nadir of $36.4 \%$ (28.5 to 44.3$)$ at $\mathrm{VO}_{2 \max }(P<0.0001)$, and then rose rapidly to a level above resting $\mathrm{StO}_{2}(82.3 \%$ (76.2 to 88.5); $P<0.0001)$ 
Table 1

Weight, $\mathrm{SpO}_{2}$ and $\mathrm{StO}_{2}$ during the exercise protocol at different altitude time points

\begin{tabular}{|c|c|c|c|c|}
\hline & \multicolumn{4}{|c|}{ Altitude } \\
\hline & Sea level & $3,500 \mathrm{~m}$ & $5,300 \mathrm{~m}-\mathrm{a}$ & $5,300 \mathrm{~m}-\mathrm{b}$ \\
\hline Number of subjects & 18 & 16 & 16 & 16 \\
\hline Weight (kg) & 79.1 (72.7 to 85.5$)$ & $78.1(71.2$ to 85.1$)$ & $78.3^{\star}(71.9$ to 84.6$)$ & $73.3^{*}(69.0$ to 77.6$)$ \\
\hline Resting $\mathrm{SpO}_{2}(\%)$ & 97.7 (97.2 to 98.2$)$ & $88.5^{\star}$ (86.8 to 90.2$)$ & $81.8^{\star}(79.8$ to 82.8$)$ & $84.3^{\star}(81.4$ to 87.2$)$ \\
\hline Resting $\mathrm{StO}_{2}(\%)$ & 74.4 (68.6 to 80.1$)$ & $58.4^{\star}(53.0$ to 63.7$)$ & 70.2 (62.3 to 78.0$)$ & $57.5^{\star}$ (49.8 to 65.1$)$ \\
\hline $\mathrm{StO}_{2}$ 3-minute ULC(\%) & $81.1^{\dagger}(73.8$ to 88.3$)$ & $65.5^{\star \dagger}(58.2$ to 72.8$)$ & $80.3^{\dagger}(73.3$ to 87.4$)$ & $69.7^{\star \star}(63.4$ to 76.0$)$ \\
\hline $\mathrm{StO}_{2} \mathrm{VO}_{2 \max }(\%)$ & $36.4^{\dagger}(28.5$ to 44.3$)$ & $24.8^{\dagger}$ (19.9 to 29.7$)$ & $52.5^{\star \dagger}(41.7$ to 63.3$)$ & $21.9^{\dagger}(12.0$ to 31.7$)$ \\
\hline $\mathrm{StO}_{2} 60$ seconds post-exercise (\%) & $82.3^{\dagger}$ (76.2 to 88.5$)$ & $64.3^{\star \dagger}(59.4$ to 69.2$)$ & $69.8^{\dagger}(63.4$ to 76.2$)$ & $63.1^{\text {*十 }}(54.8$ to 71.4$)$ \\
\hline
\end{tabular}

Data are presented as mean (95\% confidence interval). $\mathrm{SpO}_{2}$, peripheral oxygen saturation; $\mathrm{StO}_{2}$, tissue oxygen saturation; ULC, unloaded cycling; $\mathrm{VO}_{2 \text { max }}$, maximal oxygen consumption. * Significantly different from sea level. ${ }^{\dagger}$ Significantly different from the previous exercise stage.

\section{Figure 2}

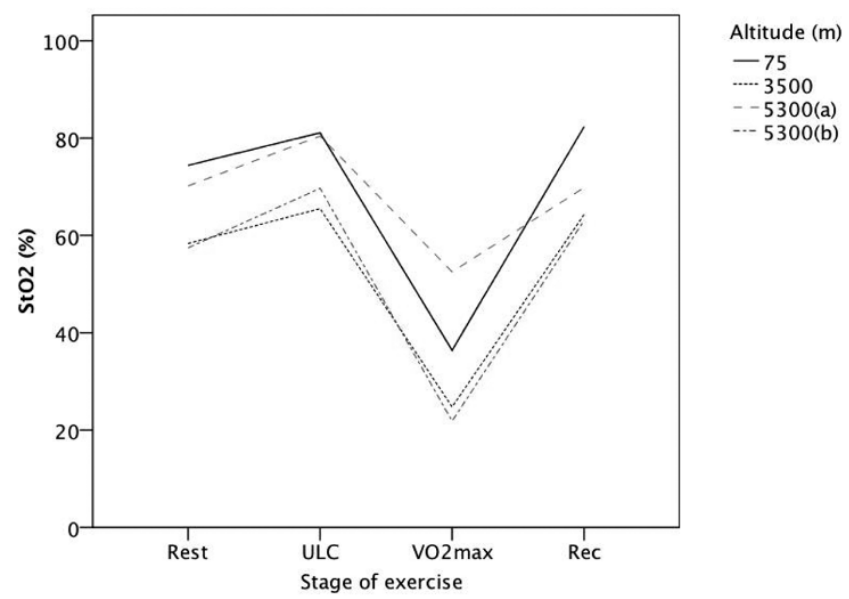

Tissue oxygen saturation at specific stages of the work protocol. Mean tissue oxygen saturation $\left(\mathrm{StO}_{2}\right)$ at specific stages of the work protocol at sea level and different altitude time points. 5300 (a), on arrival at $5,300 \mathrm{~m}$ (days 15 to 17 ); 5300 (b), before departure from $5,300 \mathrm{~m}$ (days 69 to 71); Rest, resting; ULC, after 3 minutes of unloaded cycling; $\mathrm{VO}_{2 \text { max }}$, at maximal oxygen consumption; Rec, 60 seconds after exercise has ceased.

60 seconds after exercise had ceased. At altitude the incremental exercise protocol resulted in a reproducible pattern of muscle desaturation. Figure 2 shows this pattern of change in mean $\mathrm{StO}_{2}$ at $\mathrm{SL}$ and during ascent to altitude. At 3,500 m and $5,300 \mathrm{~m}-\mathrm{b}$, the pattern was identical to SL but absolute values were approximately $15 \%$ lower at all stages of the exercise protocol. At 5,300 $\mathrm{m}$-a, the resting $\mathrm{StO}_{2}$ was only $4.2 \%$ below that observed at SL (not significant) and the pattern of change was considerably flatter than other altitudes, such that the mean $\mathrm{StO}_{2}$ at $\mathrm{VO}_{2}$ max was $16.1 \%$ higher than at SL $(P=0.043)$. Figures 3 and 4 show typical
NIRS plots (change in $\mathrm{StO}_{2}$ during exercise vs. time) from the same subject at $S L$ and at 5,300 m-b, respectively.

At 5,300 m-b there were no differences in the absolute $\mathrm{StO}_{2}$ values at any stage of exercise between climbers and the base-camp team, although climbers had a significantly higher $\mathrm{SpO}_{2}(86.6 \%$ vs. $79.2 \%$, respectively; $P=0.005)$.

\section{Tissue oxygen saturation differences between exercise stages}

The differences between mean $\mathrm{StO}_{2}$ values at different stages of exercise at $\mathrm{SL}$ and at altitude are presented in Table 2. There was no difference in $\Delta \mathrm{StO}_{2}$ between rest and $\mathrm{VO}_{2 \text { max }}$ or between ULC and $\mathrm{VO}_{2 \text { max }}$ at any altitude except $5,300 \mathrm{~m}-\mathrm{a}$, where the difference between rest and $\mathrm{VO}_{2} \max$ was $17.5 \%$, compared with $38.0 \%$ at $\mathrm{SL}(P=0.018)$.

At 5,300 m-b there was a significant difference in the $\Delta \mathrm{StO}_{2}$ value between climbers and the base-camp team from ULC to $\mathrm{VO}_{2 \text { max }}$; the base-camp team had a reduction of $62.9 \%$, compared with only $41.0 \%$ in the climbers $(P=0.031)$.

\section{Time-related tissue oxygen saturation gradient and subject rankings}

$\mathrm{StO}_{2}$ gradients $\left(\mathrm{StO}_{2}\right.$ rate values) between exercise stages at each altitude are presented in $\mathrm{Table}^{3} . \mathrm{StO}_{2}$ rate was increased at $5,300 \mathrm{~m}-\mathrm{b}$ compared with $\mathrm{SL}(P=0.008)$ but not at the other altitude time points.

At 5,300 m-b there was a significant difference in $\mathrm{StO}_{2}$ rate between climbers and the base-camp team from ULC to $\mathrm{VO}_{2 \text { max }}$; the base-camp team had a desaturation rate of $0.127 \% /$ second, compared with only $0.086 \% /$ second in the climbers $(P=0.047)$.

Subjects were numerically ranked at each altitude based on their rate of $\mathrm{StO}_{2}$ decline from the end of ULC to $\mathrm{VO}_{2}$ max. 
Figure 3

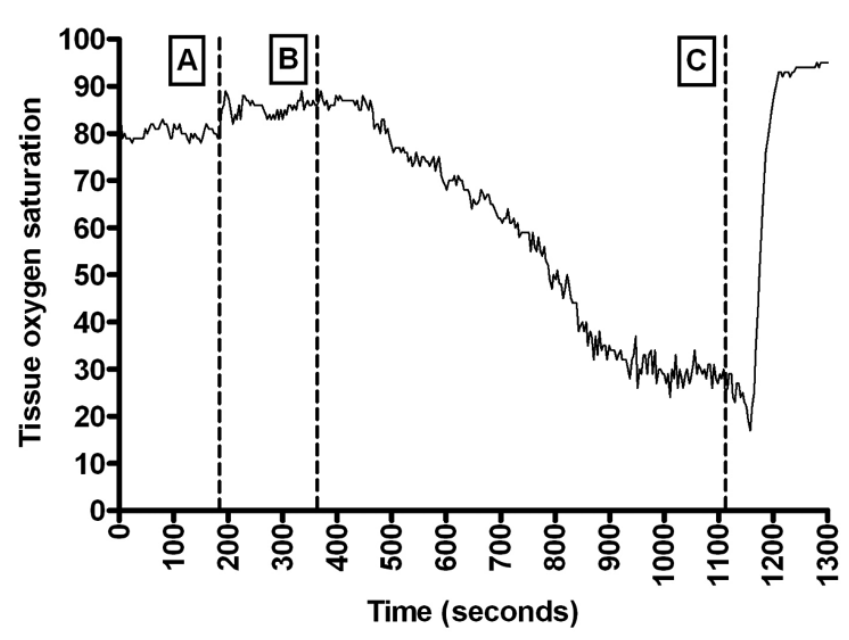

Near-infrared spectroscopy plot at sea level. Typical near-infrared spectroscopy plot from sea level $(75 \mathrm{~m})$. A, start of unloaded cycling; $\mathrm{B}$, start of loaded cycling; $\mathrm{C}$, maximum oxygen consumption.
Figure 4

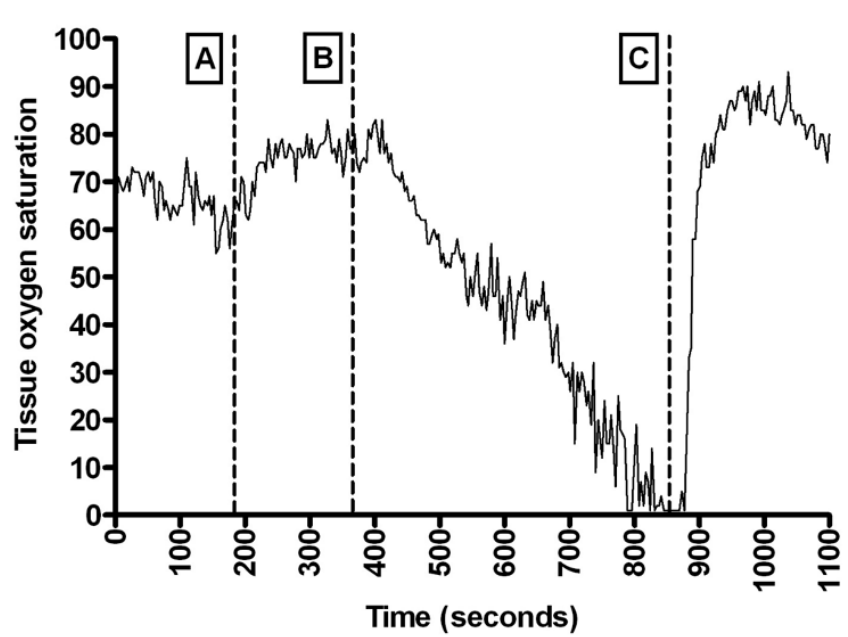

Near-infrared spectroscopy plot at altitude. Typical near-infrared spectroscopy plot from 5,300 m-b (same subject as Figure 2). A, start of unloaded cycling; $B$, start of loaded cycling; $C$, maximum oxygen consumption.

Table 2

Change in $\mathrm{StO}_{2}$ between specific stages of the exercise protocol at different altitude time points

\begin{tabular}{lcccc}
\hline & \multicolumn{3}{c}{ Altitude } \\
\cline { 2 - 5 } Difference & Sea level & $3,500 \mathrm{~m}$ & $5,300 \mathrm{~m}-\mathrm{a}$ & $5,300 \mathrm{~m}$-b \\
\hline Rest $-\mathrm{VO}_{2 \max }(\%)$ & $38.0(27.9$ to 48.1$)$ & $33.6(26.6$ to 40.6$)$ & $17.7^{\star}(10.0$ to 25.3$)$ & $35.6(24.4$ to 46.8$)$ \\
3 minutes $\mathrm{ULC}-\mathrm{VO}_{2 \max }(\%)$ & $44.7(34.2$ to 55.2$)$ & $40.7(32.2$ to 49.2$)$ & $27.8(20.2$ to 35.4$)$ & $47.8(37.5$ to 58.2$)$ \\
\hline
\end{tabular}

Data are presented as mean (95\% confidence interval). $\mathrm{StO}_{2}$, tissue oxygen saturation; ULC, unloaded cycling; $\mathrm{VO}_{2}$ max , maximal oxygen consumption. *Significantly different from sea level.

Table 3

$\mathrm{StO}_{2}$ decline between unloaded cycling and $\mathrm{VO}_{2 \text { max }}$ during exercise at different altitude time points

\begin{tabular}{|c|c|c|c|c|}
\hline & \multicolumn{4}{|c|}{ Altitude } \\
\hline & Sea level & $3,500 \mathrm{~m}$ & $5,300 \mathrm{~m}-\mathrm{a}$ & $5,300 \mathrm{~m}-\mathrm{b}$ \\
\hline $\begin{array}{l}\mathrm{StO}_{2} \text { rate from ULC to } \mathrm{VO}_{2 \max } \\
\text { (\%/second) }\end{array}$ & $0.063(0.047$ to 0.080$)$ & 0.067 (0.050 to 0.083$)$ & $0.056(0.041$ to 0.072$)$ & $0.099(0.078 \text { to } 0.120)^{*}$ \\
\hline
\end{tabular}

Data are presented as mean (95\% confidence interval). $\mathrm{StO}_{2}$, tissue oxygen saturation; ULC, unloaded cycling; $\mathrm{VO}_{2}$ max , maximal oxygen consumption. *Significantly different from sea level $(P<0.05)$.

Rankings were compared at each altitude by Spearman's rank correlation coefficient. There was a significant correlation between the subject rank order at SL when compared with $3,500 \mathrm{~m}$ (correlation coefficient $=0.780, P=0.002$ ), compared with $5,300 \mathrm{~m}$-a (correlation coefficient $=0.688$, $P=0.007$ ) and compared with $5,300 \mathrm{~m}-\mathrm{b}$ (correlation coefficient $=0.41, P=0.041$ ).

\section{Relationship between tissue oxygen saturation and peripheral oxygen saturation}

There was no correlation between the resting $\mathrm{SpO}_{2}$ and the resting $\mathrm{StO}_{2}$ at any altitude. There was a correlation, however, between resting $\mathrm{SpO}_{2}$ and $\mathrm{StO}_{2}$ at $\mathrm{VO}_{2}$ max at $5,300 \mathrm{~m}-\mathrm{b}(r=0.557, P=0.019)$. At $5,300 \mathrm{~m}-\mathrm{b}$ there was also a negative correlation between the resting $\mathrm{SpO}_{2}$ and 
$\mathrm{StO}_{2 \text { rate }}(r=-0.562, P=0.023)$, such that those individuals with a lower resting $\mathrm{SpO}_{2}$ desaturated more rapidly during exercise.

\section{Discussion}

\section{Summary of findings}

The present study demonstrated in selected individuals that NIRS could be used to measure skeletal muscle $\mathrm{StO}_{2}$ in the vastus lateralis during exhaustive exercise and to generate reproducible results in the hypoxic environment encountered at high altitude. Three minutes of unloaded exercise at SL led to a small rise in $\mathrm{StO}_{2}$ that progressively declined as the exercise workload increased. $\mathrm{StO}_{2}$ reached a plateau shortly before $\mathrm{VO}_{2 \text { max }}$ was achieved, and then, following cessation of exercise, rapidly recovered to a level above the resting value.

Figures 3 and 4 show typical examples of the change in $\mathrm{StO}_{2}$ during unloaded and loaded exercise at different altitudes. At $3,500 \mathrm{~m}$, the absolute changes in $\mathrm{StO}_{2}$ were similar to those at SL but values were approximately $15 \%$ lower at rest and throughout exercise. On arrival at higher altitude (5,300 m-a), the resting $\mathrm{StO}_{2}$ was similar to that at $\mathrm{SL}$ and the changes during exercise $\left(\Delta \mathrm{StO}_{2}\right.$ values) were considerably less marked than those observed at SL, giving the appearance of a flattened pattern of $\mathrm{StO}_{2}$ (Figures 1 and 2). By the end of the expedition $(5,300 \mathrm{~m}-\mathrm{b})$, days 69 to 71 at altitude, the pattern was similar to that observed at SL and at $3,500 \mathrm{~m}$ (that is, $\Delta \mathrm{StO}_{2}$ unchanged) except that the time-related decline in $\mathrm{StO}_{2}\left(\mathrm{StO}_{2}\right.$ rate $)$ during exercise was significantly more rapid than that at $\mathrm{SL}(P=0.008)$.

At altitude, the maximum exercise capacity was reduced leading to a reduction in $\mathrm{VO}_{2}$ max as has been previously documented [7-10,15] - and the decline in $\mathrm{VO}_{2} \max$ was proportional to elevation.

\section{Study limitations}

There were marked interindividual differences in absolute $\mathrm{StO}_{2}$ values at rest and during exercise (Table 1). One reason for these differences is related to the fact that nearinfrared light emitted by and received by the spectrometer probe has an unknown pathlength, and therefore the absolute $\mathrm{StO}_{2}$ cannot be calculated [16]. Furthermore, significant heterogeneity in oxygenation has been demonstrated both within and between specific muscles so probe placement on the thigh is important and may have a significant effect upon results [17-19]. $\mathrm{StO}_{2}$ is therefore a value that is specific to the tissue beneath an individual probe. As a result of this, comparison of absolute $\mathrm{StO}_{2}$ values between individuals is of limited value. The relative changes in $\mathrm{StO}_{2}$ as a result of specific stimuli $\left(\Delta \mathrm{StO}_{2}\right)$, and the rate of change in the response $\left(\mathrm{StO}_{2}\right.$ rate $)$, however, may provide valuable insight into the dynamics of oxygen supply and demand in a subject.

The depth of tissue beneath the spectrometer probe that near-infrared light can penetrate is directly related to the distance between the illumination and detection fibres (optodes) of the device. The banana-shaped light beam has a maximum depth of approximately one-half the distance between the optodes [20]. The InSpectra ${ }^{\mathrm{TM}}$ Tissue Spectrometer was fitted with a $15 \mathrm{~mm}$ probe, which means the maximum depth of penetration was approximately $7.5 \mathrm{~mm}$. For some individuals this may not represent muscle tissue oxygenation but overlying adipose tissue or skin. This factor may further increase the interindividual variation in the NIRS signal. Most of the NIRS plots that were rejected as a result of minimal change in oxygenation throughout exercise were from females; this has been previously noted as a substantial confounding factor during skeletal muscle NIRS studies [21]. Other authors also report needing to remove subjects from the final analysis as a result of poor signal response due to excessive subcutaneous adipose tissue [14]. Validated objective criteria for rejection of nonphysiological NIRS data do not exist. Subjective removal of data may therefore confound results; however, data removal was performed without the knowledge of the subject or altitude identification.

As the NIRS light beam must pass through skin during both emission and reflection, skin blood flow and oxygenation will contribute to the overall NIRS signal [22,23]. Ambient laboratory temperature may therefore have exerted an effect on results by inducing vasoconstriction within the skin at low temperature. All studies were performed in purpose-built insulated temporary laboratories where the average temperature throughout the 3-month expedition was $24.1^{\circ} \mathrm{C}$ at $\mathrm{SL}, 19.6^{\circ} \mathrm{C}$ at $3,500 \mathrm{~m}$ and $21.5^{\circ} \mathrm{C}$ at $5,300 \mathrm{~m}$. Diurnal temperature variation may have resulted in temperatures considerably lower than these mean values for those tests performed early in the morning at altitude. The preliminary warm-up exercise protocol, however, should have provided sufficient stimulus to negate the effect of cold-induced vasoconstriction.

\section{Interpretation of results}

Although a rarely regarded tissue in the critically ill patient, early reduction in skeletal muscle $\mathrm{StO}_{2}$ detected by NIRS has been shown to herald poor outcome by identifying patients at risk of infectious complications or multiple organ failure [24]. Rather than a quantitative measurement of tissue oxygenation, however, the $\mathrm{StO}_{2}$ value derived from a NIRS signal reflects the localised equilibrium of oxygen delivery and utilisation [25] and closely follows regional venous oxygenation $[14,26]$. Furthermore, correlation between changes in the continuous-wave NIRS signal and that of ${ }^{31} \mathrm{P}$ magnetic resonance spectroscopy [25] and of ${ }^{1} \mathrm{H}$ nuclear magnetic resonance [27] suggests that NIRS can be used effectively in the evaluation of localised muscle oxidation. As a measure of oxygen saturation, $\mathrm{StO}_{2}$ could be regarded as a surrogate marker for tissue oxygen content, therefore indicating crude alterations in tissue oxygen extraction. Previous work has demonstrated that acute exposure to hypoxia results in a 
greater degree of skeletal muscle deoxygenation during exercise when compared with normoxia [28].

The change in absolute $\mathrm{StO}_{2}$ observed in the present study at SL has been previously reported by other authors at SL; typically, there is an initial increase in oxygenation followed by a decline until the minimum plateau value at $\mathrm{VO}_{2}$ max $[4,14,29]$. The commonly observed plateau of $\mathrm{StO}_{2}$ shortly before $\mathrm{VO}_{2 \text { max }}$ at $\mathrm{SL}$ (Figure 3) tended not to be as prominent at 5,300 m-b (Figure 4), although this was difficult to quantify. The significance of this plateau has been suggested as representing the limit of tissue oxygen extraction $[14,28]$. The relationship between maximal oxygen extraction and $\mathrm{VO}_{2} \max$ may therefore be altered after prolonged exposure to hypoxia and requires more detailed investigation. Similar values for $\Delta \mathrm{StO}_{2}$ at $\mathrm{SL}, 3,500 \mathrm{~m}$ and $5,300 \mathrm{~m}$-b suggest that the overall balance between oxygen delivery and utilisation at these altitude time points were similar. Oxygen delivery exceeded utilisation during ULC, resulting in an increase in $\mathrm{StO}_{2}-$ but as the work rate increased the situation was reversed, until the peri- $\mathrm{VO}_{2 \text { max }}$ plateau when oxygen extraction was maximal and exhaustion was imminent.

The relatively high resting $\mathrm{StO}_{2}$ and reduced $\Delta \mathrm{StO}_{2}$ between rest and $\mathrm{VO}_{2 \text { max }}$ observed at 5,300 m-a (Figures 1 and 2) is not in keeping with the findings at $3,500 \mathrm{~m}$ and $5,300 \mathrm{~m}-\mathrm{b}$. Identical equipment, protocols and investigators were used on arrival at and departure from 5,300 m, so technical failure or inaccuracy seems unlikely. Limited ability to extract oxygen could account for the reduced $\Delta \mathrm{StO}_{2}$ value; however, the reason for this on arrival at $5,300 \mathrm{~m}$ is unclear. One hypothesis is that the small gain in weight observed from $3,500 \mathrm{~m}$ to $5,300 \mathrm{~m}$ may represent a degree of tissue oedema that could increase oxygen diffusion limitation in muscle tissue. The usual response of ascent to altitude is generally weight loss [30]; the gain in weight observed, or certainly the lack of loss, could therefore be tissue fluid accumulation, frequently observed in those affected detrimentally by high altitude [31]. The rate of decline in $\mathrm{StO}_{2}$ during loaded exercise (end of ULC to $\mathrm{VO}_{2 \max }$ ), as presented in Table 3 , is significantly more rapid at 5,300 m-b than at SL. This more rapid rate of decline was not seen on arrival at the same altitude 50 days previous to the departure measurements despite the small rise in mean $\mathrm{SpO}_{2}$ at $5,300 \mathrm{~m}-\mathrm{b}(P=0.002)$. Weight loss at altitude results in a greater proportion of lean tissue mass than fat mass [30], which leads to a reduction in the skeletal muscle fibre cross-sectional area [32]. In the group investigated in the present study, mean weight loss during the expedition was $5.8 \mathrm{~kg}$ in 72 days $(P<0.001)$.

At 5,300 m-b, those subjects with a lower resting $\mathrm{SpO}_{2}$ showed a more rapid rate of $\mathrm{StO}_{2}$ desaturation during exercise. One explanation for this could be that individuals with a low $\mathrm{SpO}_{2}$ at rest had reduced systemic oxygen availability due either to a blunted hypoxic ventilatory response or to an increased arterial-alveolar oxygen partial pressure difference. Following acclimatisation to high altitude, however, cardiac output remains unchanged from SL values for a given work load throughout exercise [9,33], and the arterial oxygen content remains above SL values [34,35] even at maximal exercise [36]. This implies that systemic oxygen delivery remains similar to that experienced at SL under conditions similar to those experienced by the subjects in this study. More distal mechanisms in the oxygen cascade - such as alterations in regional and/or microcirculatory blood flow, changes in the affinity of oxygen to haemoglobin or diffusion limitation within skeletal muscle tissue - may therefore be responsible for the observed findings.

At the end of the expedition $(5,300 \mathrm{~m}-\mathrm{b})$ the base-camp team who remained at 5,300 $\mathrm{m}$ after ascent were found to have a significantly greater $\Delta \mathrm{StO}_{2}$ and $\mathrm{StO}_{2}$ rate of decline during exercise than the climbers who ascended above 5,300 m. In the climbing cohort, the exposure to severe hypoxia at altitudes up to $8,848 \mathrm{~m}$ is likely to have induced a greater rise in haemoglobin than the base-camp team, thus increasing arterial oxygen content and preventing such a precipitous fall in skeletal muscle oxygenation during exercise. Alternatively, exposure to such hypoxic conditions may trigger a process of hypoxic preconditioning that affords a degree of protection following descent to lower heights.

In the clinical setting, abnormal heterogeneous blood flow in the sublingual microcirculation of critically ill patients [37-39] may account for the imbalance between oxygen delivery and consumption in this pathological state [40]. Reduced sublingual microcirculatory blood flow has been observed in climbers ascending to high altitude [41]. If abnormal blood flow also exists in skeletal muscle microvasculature, one could postulate that it may lead to a reduction in tissue oxygen delivery and hence in $\mathrm{StO}_{2}$.

\section{Conclusion}

NIRS is a useful tool for studying thigh skeletal muscle oxygenation during exercise but is limited by the depth of beam penetration in some individuals. The pattern of absolute change in exercising muscle $\mathrm{StO}_{2}$ on exposure to altitude is similar to that at $\mathrm{SL}$ and, despite the reduction in exercise capacity, demonstrates a similar reduction in $\mathrm{StO}_{2}$ from rest to maximal exertion. The rate of desaturation is more rapid after prolonged exposure to altitude (69 to 71 days), and at this altitude time point a lower resting $\mathrm{SpO}_{2}$ was associated with a more rapid rate of $\mathrm{StO}_{2}$ decline during exercise. Exposure to extreme hypoxia above $5,300 \mathrm{~m}$ appears to have a protective effect in reducing the degree of muscle desaturation during exercise on return to $5,300 \mathrm{~m}$.

These findings suggest that mechanisms within the peripheral circulation or tissues govern local tissue oxygen flux and utilisation. Alterations at the distal portion of the oxygen cascade may be an important component of adaptation or maladaptation to chronic hypoxia secondary to high altitude 
exposure and disease. The heterogeneity of individual responses to chronic hypoxia may therefore be explained by changes in the peripheral circulation rather than the systemic circulation in both scenarios.

\section{Competing interests}

MM and MPWG have received unrestricted research support from Hutchinson Technology.

\section{Acknowledgements}

The Caudwell Xtreme Everest Research Group wishes to express their heartfelt thanks to the trekkers and Sherpas who made this study possible. Supported by Mr John Caudwell, BOC Medical (now part of Linde Gas Therapeutics), Eli Lilly, the London Clinic, Smiths Medical, Deltex Medical, and the Rolex Foundation (unrestricted grants), the Association of Anaesthetists of Great Britain and Ireland, the United Kingdom Intensive Care Foundation, and the Sir Halley Stewart Trust. DM is a Critical Care Scholar of the London Clinic, and DZHL is a Fellow of the Association of Anaesthetists of Great Britain and Ireland. Some of this work was undertaken at University College London Hospital-University College London Comprehensive Biomedical Research Centre, which received a proportion of funding from the UK Department of Health's National Institute for Health Research Biomedical Research Centre's funding scheme. The Caudwell Xtreme Everest volunteers who trekked to Everest Base Camp also kindly donated to support the research. Caudwell Xtreme Everest is a research project coordinated by the Centre for Altitude, Space, and Extreme Environment Medicine, University College London. Membership, roles, and responsibilities of the Caudwell Xtreme Everest Research Group can be found at www.caudwell-xtreme-everest.co.uk/team.

This article is part of Critical Care Volume 13 Supplement 5: Tissue oxygenation $\left(\mathrm{StO}_{2}\right)$ in healthy volunteers and critically-ill patients. The full contents of the supplement are available online at http://ccforum. com/supplements/13/S5. Publication of the supplement has been supported with funding from Hutchinson Technology Inc.

\section{References}

1. Grocott M, Montgomery $\mathrm{H}$, Vercueil A: High-altitude physiology and pathophysiology: implications and relevance for intensive care medicine. Crit Care 2007, 11:203.

2. Ferretti G, Antonutto G, Denis C, Hoppeler H, Minetti AE, Narici $M V$, Desplanches $D$ : The interplay of central and peripheral factors in limiting maximal $\mathrm{O}_{2}$ consumption in man after prolonged bed rest. J Physiol 1997, 501:677-686.

3. Mancini DM, Bolinger L, Li H, Kendrick K, Chance B, Wilson JR: Validation of near-infrared spectroscopy in humans. J Appl Physiol 1994, 77:2740-2747.

4. Belardinelli R, Barstow TJ, Porszasz J, Wasserman K: Changes in skeletal muscle oxygenation during incremental exercise measured with near infrared spectroscopy. Eur J Appl Physiol Occup Physiol 1995, 70:487-492.

5. Bhambhani $Y$, Maikala R, Esmail S: Oxygenation trends in vastus lateralis muscle during incremental and intense anaerobic cycle exercise in young men and women. Eur J Appl Physiol 2001, 84:547-556.

6. Grassi B, Quaresima V, Marconi C, Ferrari M, Cerretelli P: Blood lactate accumulation and muscle deoxygenation during incremental exercise. J Appl Physio/ 1999, 87:348-355.

7. Cerretelli P: Limiting factors to oxygen transport on Mount Everest. J Appl Physiol 1976, 40:658-667.

8. Pugh LGCE, Gill MB, Lahiri S, Milledge JS, Ward MP, West JB: Muscular exercise at great altitudes. J Appl Physiol 1964, 19:431-440.

9. Sutton JR, Reeves JT, Wagner PD, Groves BM, Cymerman A, Malconian MK, Rock PB, Young PM, Walter SD, Houston CS: Operation Everest II: oxygen transport during exercise at extreme simulated altitude. J Appl Physiol 1988, 64:13091321.

10. West JB, Boyer SJ, Graber DJ, Hackett PH, Maret KH, Milledge JS, Peters RMJ, Pizzo CJ, Samaja M, Sarnquist FH, et al.: Maximal exercise at extreme altitudes on Mount Everest. J Appl Physiol 1983, 55:688-698.
11. Roach RC, Maes D, Sandoval D, Robergs RA, Icenogle M, Hinghofer-Szalkay H, Lium D, Loeppky JA: Exercise exacerbates acute mountain sickness at simulated high altitude. J Appl Physiol 2000, 88:581-585.

12. ATS/ACCP statement on cardiopulmonary exercise testing. Am J Respir Crit Care Med 2003, 167:211-277.

13. Hansen JE, Sue DY, Wasserman K: Predicted values for clinical exercise testing. Am Rev Respir Dis 1984, 129:S49-S55.

14. Wilson JR, Mancini DM, McCully K, Ferraro N, Lanoce V, Chance $B$ : Noninvasive detection of skeletal muscle underperfusion with near-infrared spectroscopy in patients with heart failure. Circulation 1989, 80:1668-1674.

15. Ferretti G, Moia C, Thomet JM, Kayser B: The decrease of maximal oxygen consumption during hypoxia in man: a mirror image of the oxygen equilibrium curve. J Physiol 1997, 498:231-237.

16. Delpy DT, Cope M: Quantification in tissue near-infrared spectroscopy. Philos Trans Biol Sci 1997, 352:649-659.

17. Cooper CE, Springett R: Measurement of cytochrome oxidase and mitochondrial energetics by near-infrared spectroscopy. Philos Trans R Soc Lond B Biol Sci 1997, 352:669-676.

18. Miura H, McCully K, Hong L, Nioka S, Chance B: Regional difference of muscle oxygen saturation and blood volume during exercise determined by near infrared imaging device. Jpn J Physiol 2001, 51:599-606.

19. Miura H, McCully K, Nioka S, Chance B: Relationship between muscle architectural features and oxygenation status determined by near infrared device. Eur J Appl Physiol 2004, 91: 273-278

20. Miura H, McCully K, Chance B: Application of multiple NIRS imaging device to the exercising muscle metabolism. Spectroscopy 2003, 17:549-558.

21. van Beekvelt MC, Borghuis MS, van Engelen BG, Wevers RA, Colier WN: Adipose tissue thickness affects in vivo quantitative near-IR spectroscopy in human skeletal muscle. Clin Sci (Lond) 2001, 101:21-28.

22. Buono MJ, Miller PW, Hom C, Pozos RS, Kolkhorst FW: Skin blood flow affects in vivo near-infrared spectroscopy measurements in human skeletal muscle. Jpn J Physio/ 2005, 55: 241-244,

23. Davis SL, Fadel PJ, Cui J, Thomas GD, Crandall CG: Skin blood flow influences near-infrared spectroscopy-derived measurements of tissue oxygenation during heat stress. J App/ Physiol 2006, 100:221-224.

24. Ikossi DG, Knudson MM, Morabito DJ, Cohen MJ, Wan JJ, Khaw L, Stewart CJ, Hemphill C, Manley GT: Continuous muscle tissue oxygenation in critically injured patients: a prospective observational study. J Trauma 2006, 61:780-788; discussion 788-790.

25. Hamaoka $T$, Iwane $H$, Shimomitsu $T$, Katsumura $T$, Murase $N$, Nishio S, Osada T, Kurosawa Y, Chance B: Noninvasive measures of oxidative metabolism on working human muscles by near-infrared spectroscopy. J Appl Physiol 1996, 81:14101417.

26. Esaki K, Hamaoka T, Radegran G, Boushel R, Hansen J, Katsumura T, Haga S, Mizuno M: Association between regional quadriceps oxygenation and blood oxygen saturation during normoxic one-legged dynamic knee extension. Eur J Appl Physiol 2005, 95:361-370.

27. Tran TK, Sailasuta N, Kreutzer U, Hurd R, Chung Y, Mole P, Kuno $S$, Jue T: Comparative analysis of NMR and NIRS measurements of intracellular $\mathrm{PO}_{2}$ in human skeletal muscle. $A m J$ Physiol 1999, 276:R1682-R1690.

28. Subudhi AW, Dimmen AC, Roach RC: Effects of acute hypoxia on cerebral and muscle oxygenation during incremental exercise. J App/ Physio/ 2007, 103:177-183.

29. Matsui S, Tamura N, Hirakawa T, Kobayashi S, Takekoshi N, Murakami E: Assessment of working skeletal muscle oxygenation in patients with chronic heart failure. Am Heart $J$ 1995, 129:690-695.

30. Boyer SJ, Blume FD: Weight loss and changes in body composition at high altitude. J Appl Physiol 1984, 57:1580-1585.

31. Maggiorini M, Buhler B, Walter M, Oelz O: Prevalence of acute mountain sickness in the Swiss Alps. Br Med J 1990, 301:853855.

32. Hoppeler H, Kleinert E, Schlegel C, Claassen H, Howald H, Kayar SR, Cerretelli P: Morphological adaptations of human skeletal 
muscle to chronic hypoxia. Int J Sports Med 1990, 11(Suppl 1):S3-S9.

33. Pugh LGCE: Cardiac output in muscular exercise at $\mathbf{5 , 8 0 0 ~} \mathrm{m}$ (19,000 ft). J App/ Physiol 1964, 19:441-447.

34. Lundby C, Boushel R, Robach P, Moller K, Saltin B, Calbet JA: During hypoxic exercise some vasoconstriction is needed to match $\mathrm{O}_{2}$ delivery with $\mathrm{O}_{2}$ demand at the microcirculatory level. J Physio/ 2008, 586:123-130.

35. Lundby C, Calbet JA, van Hall G, Saltin B, Sander M: Pulmonary gas exchange at maximal exercise in Danish lowlanders during 8 wk of acclimatization to $4,100 \mathrm{~m}$ and in high-altitude Aymara natives. Am J Physiol Regul Integr Comp Physiol 2004, 287:R1202-R1208.

36. Calbet JA, Boushel R, Radegran G, Sondergaard H, Wagner PD, Saltin $\mathrm{B}$ : Why is $\mathrm{VO}_{2}$ max after altitude acclimatization still reduced despite normalization of arterial $\mathrm{O}_{2}$ content? $\mathrm{Am} \mathrm{J}$ Physiol Regul Integr Comp Physiol 2003, 284:R304-R316.

37. De Backer D, Creteur J, Preiser JC, Dubois MJ, Vincent JL: Microvascular blood flow is altered in patients with sepsis. $\mathrm{Am}$ J Respir Crit Care Med 2002, 166:98-104.

38. Trzeciak S, Rivers EP: Clinical manifestations of disordered microcirculatory perfusion in severe sepsis. Crit Care 2005, 9 (Suppl 4):S20-S26.

39. Spronk PE, Ince C, Gardien MJ, Mathura KR, Oudemans-van Straaten HM, Zandstra DF: Nitroglycerin in septic shock after intravascular volume resuscitation. Lancet 2002, 360:13951396.

40. Ince C: The microcirculation is the motor of sepsis. Crit Care 2005, 9(Suppl 4):S13-S19.

41. Martin DS, Ince C, Goedhart P, Levett DZ, Grocott MP: Abnormal blood flow in the sublingual microcirculation at high altitude. Eur J Appl Physiol 2009, 106:473-478. 